laboratory research, both before and during the War, and covering such subjects as rheumatic fever, influenza and typhus.

British Council Office in China: Mr. C. M. G. Bolton

Mr. C. M. G. Borton has left for China to join the staff of the British Council in Chungking as a geological specialist. Born in Plymouth in 1904, the son of the late Commander A. W. Bolton, R.N., from Berkhamsted School he went to Merton College, Oxford, and graduated in the Honours School of Natural Science in geology. He worked with the Anglo-Iranian Oil Company in Persia, and later was field geologist to the Finsbury Pavement House group of mining companies, working in the Gold Coast area, and was associated with oil-boring in Sussex. In 1940 he joined the R.A.F. and served in Iceland, where he studied the geology, and in 1942 was appointed to the Military Mission in Moscow. In 1944 he was seconded to a military unit to carry out researches on military geology. Mr. Bolton is a fellow of the Geological Society and an associate member of the Institute of Petroleum. As a practising field geologist, he has travelled widely-across Persia from the Persian Gulf to the Caspian Sea and beyond to Moscow, twice across the Sahara from West Africa to Algeria and Morocco, across Africa from West Africa to Kenya, and through the Sudan and the Levant.

Secretary of the American Chemical Society: Mr. A. H. Emery

Mr. Alden Hayes Emery has been elected secretary and business manager of the American Chemical Society. Mr. Emery, a former official of the United States Bureau of Mines, succeeds Dr. Charles L. Parsons, who retired on December 31 after serving the Society as secretary for thirty-eight years and as business manager for fourteen. Mr. Emery has been the Society's assistant manager since 1936 and assistant secretary since 1943. Born in Lancaster, N.H., on June 2, 1901, he graduated in 1922 from Oberlin College, where he specialized in chemistry, and obtained his master's degree from Ohio State University in 1923. Mr. Emery then joined the staff of the Bureau of Mines as a chemist at the Pittsburgh Experiment Station. In 1927 he went to Washington to take up administrative work in the Bureau. When he resigned in 1936 to become assistant manager of the American Chemical Society, he was assistant chief engineer of the Bureau's Experiment Stations Division. Mr. Emery was secretary of the American Chemical Society's Division of Gas and Fuel Chemistry during 1933-37, and was assistant editor of Chemical Abstracts in charge of its fuel section during 1931-39. $\mathrm{He}$ has also edited several sections of Metallurgical Abstracts dealing with the chemical aspects of metallurgy. As a member of the American Institute of Mining and Metallurgical Engineers, he helped to establish the Institute's Industrial Minerals Division, of which he was secretary in 1938 and vice-chairman in 1939.

\section{Meteorological Research in Australia}

RESEARCH in Australia in the fields of meteorology and atmospheric physics has been receiving active attention recently. Present proposals envisage a subdivision of research between the Meteorological Bureau, the University of Melbourne, and the Council for Scientific and Industrial Research. The Meteoro- logical Bureau is concerned with applied meteorology and climatology for public, economic and defence interests, and is carrying out research on problems connected with its practical functions. During the War it has extended its studies to include intensive investigations in areas to the north of the Australian continent. The School of Meteorology at the University of Melbourne provides theoretical post-graduate training in meteorology, and is undertaking research into problems associated with aeronautical meteorology and other problems of a long-range nature referred to it by the Meteorological Bureau.

It is now proposed that the Council for Scientific and Industrial Research shall establish a Section of Meteorological Physics to concentrate on fundamental research into the physics of the atmosphere. The research work of the three organisations will be coordinated by a Meteorological Research Consultative Committee. As a first step, the Council for Scientific and Industrial Research is appointing an officer to take charge of this new phase of its activities, and it hopes to develop in Australia a research laboratory devoted to meteorological physies.

\section{Summer School in Social Biology}

THE British Social Hygiene Council is holding a residential summer school in social biology, at Wadham College, Oxford, during August 1-15. The School is being planned to illustrate the scientific approach, through biology, to human life and culture, as well as the ways in which the biological sciences find application in individual and social life. It is designed to appeal to teachers in all types of schools, along with others concerned with education: youth leaders, nurses, welfare workers, people in administrative positions and members of the general public. The main course of lectures will deal with broad aspects of social biology of interest to specialists and laymen alike. The evening lectures will be given by distinguished visiting biologists and social workers, each speaking on work and problems in his own particular field. At the Sunday sessions a special feature will be the discussions on the relation of biological science to ethical and spiritual values.

At the first session each day members will be able to attend either an instructional course in elementary biology, to extend their basic knowledge, or talks and discussions dealing with present-day social and cultural aspects of biology. These alternative courses will be supplemented by tea-time sessions at which speakers will discuss class-room problems of teaching biology and the scope for the biological approach to certain social questions. A series of practical demonstrations, and of visits to scientific institutions, research departments and other places of interest, in and around Oxford, is being arranged. An intro. ductory course in animal dissection will also be offered, if there is sufficient call for it. Social arrange. ments are also being made. For the whole Summer School, apart from dissections, the inclusive fee will be $£ 14$ 14s. Further details can be obtained from the British Social Hygiene Council, Tavistock House North, London, W.C.l.

\section{Summer School in Health Education}

THE Central Council for Health Education will hold one residential summer school in England, this year, at Somerville College, Oxford, during August 14-28 inclusive. The directors of the school will be Miss D. F. M. Gardner, head of the Child Development Department, University of London Institute of Educa- 